\title{
A APLICABILIDADE DO MODELO DE GOVERNANÇA DE TECNOLOGIA DA INFORMAÇÃO: O CASO UNP
}

\author{
B. R. R. GRANJEIRO* e L. F. L. G. COSTA \\ Instituto Federal de Educação, Ciência e Tecnologia do Rio Grande do Norte \\ brenoricardoif@gmail.com*
}

Artigo submetido em abril/2016 e aceito em julho/2016

DOI: 10.15628/empiricabr.2016.4413

\begin{abstract}
RESUMO
Nos últimos anos, com as mudanças ocorridas nas estruturas organizacionais, pode-se perceber que a área de Tecnologia da Informação passou a ser um dos componentes importantes nas empresas, e o uso da Governança de Tecnologia da Informação tem ganhado destaque, pois ela possibilita maior competitividade e alinhamento das iniciativas de TI com a estratégia do negócio. A Governança de Tecnologia da Informação se trata de um conjunto de processos para avaliar e direcionar o uso da TI para dar suporte à organização e monitorar seu uso para realizar planos. Este trabalho apresenta um estudo de caso de caráter descritivo e exploratório que teve o objetivo de analisar como o modelo de governança de TI se aplica a instituição Universidade Potiguar (UnP), localizada no município de Natal, no Rio Grande do Norte, bem como entender e explicar os aspectos que o norteiam, desde a origem da governança corporativa, como também a visão geral do modelo, definindo as suas caraterísticas e também compreender o uso de tal mecanismo com relação em gerar vantagem competitiva para a instituição. Para isso, foram analisados esses aspectos através de uma entrevista semiestruturada, respondendo a
\end{abstract}

pergunta problema. Pode-se concluir que a área de TI serve de apoio à estrutura educacional da instituição, pois ela está diretamente ligada com metas e estratégia da Instituição, e se subdivide em cinco setores principais: Operações de TI; Security Office, Escritório de Projetos, Desenvolvimento de Sistemas e de Controles Internos de TI. A implantação do modelo na instituição ocorreu alinhada com o uso dos modelos de melhores práticas para aplicação da governança sendo eles: Control Objectives for Information and related Technology (COBIT); Information Technology Infrastructure Library (ITIL); Project Management Body of Knowledge (PMBOK), ISO2700 e Scrum, e o uso desse modelo garante integridade, disponibilidade, confiabilidade e confidencialidade dos serviços, informações e sistemas. Outro fato que se pode concluir que em relação ao uso do modelo de governança para obter vantagem competitiva, observou-se que é preciso garantir que a GTI exista efetivamente na organização e que esteja nos requisitos de compliance, o que garante uma melhor colocação no mercado, além de garantir que os recursos estão sendo utilizados da maneira correta.

PALAVRAS-CHAVE: Governança corporativa, Tecnologia da informação, Governança de tecnologia da informação, Vantagem competitiva.

\section{THE APPLICABILITY MODEL OF INFORMATION TECHNOLOGY GOVERNANCE: THE UNP CASE}

\section{ABSTRACT}

In recent years, with changes in organizational structures, it can be seen that the area of Information Technology has become one of the important components in business, and the use of Information Technology Governance has gained prominence because it allows greater competitiveness and aligning IT initiatives with business strategy. The Governance of Information Technology it is a set of processes to evaluate and direct the use of IT to support the organization and monitor its use to make plans. This paper presents a descriptive and exploratory case study that aimed to analyze how the IT governance model applies the institution Universidade Potiguar (UNP) located in Natal, Rio Grande do Norte and understand and explain the aspects that guide, since the origin of corporate governance, as well as the overview of the model, defining its features and also understand the use of such a mechanism with respect to generate competitive advantage for the institution. For this, these aspects were analyzed through a semistructured interview, answering the question problem. It can be
\end{abstract}

concluded that the IT department serves to support the educational structure of the institution, because it is directly linked with goals and strategy of the institution, and is divided into five main sectors: IT Operations; Security Office, Project Office, Systems Development and Internal controls. The implementation of the model in the institution was in line with the use of best practice models for implementation of governance which are: Control Objectives for Information and related Technology (COBIT); Information Technology Infrastructure Library (ITIL); Project Management Body of Knowledge (PMBOK), ISO2700 and Scrum, and using this model ensures integrity, availability, reliability and confidentiality of services, information and systems. Another fact that can be concluded that in relation to the use of the governance model for competitive advantage, it was observed that it is necessary to ensure that the GTI effectively exists in the organization and is in compliance requirements, which guarantees a better placing on the market and ensures that the funds are being used properly.

KEYWORDS: Corporate Governance, Information technology, Information technology governance, Competitive advantage. 


\section{INTRODUÇÃO}

O termo Governança Corporativa começou a ser discutido a partir do surgimento de vários escândalos em grandes empresas na década de 80 e 90, inicialmente nos Estados Unidos, onde se caracterizou por um movimento de acionistas e investidores com o objetivo de se protegerem dos abusos praticados pela diretoria executiva das empresas, da estagnação dos conselhos de administração e das omissões das auditorias externas, assim despertando a busca pela criação de um conjunto de regras e de sistemas de monitoramento interno e externo que impedissem tais ações. (Instituto Brasileiro de Governança Corporativa, 2009).

Segundo Steinberg (2003), o tema passou a ser mais discutido com o caso da empresa norte americana de energia Enron em 2002, que fraudou os resultados dos balanços para elevar o valor das suas ações, e com isso, tornou-se aparente a falta de transparência da empresa com seus investidores. Com isso, houve a criação da lei Sarbanes-Oxley (SOX) nos Estados Unidos, que visa à proteção contra esses tipos de fraudes (OLIVEIRA, 2006).

Dentro desse contexto, de acordo com o Instituto Brasileiro de Governança Corporativa (2009), a governança corporativa surge com o objetivo estabelecer um conjunto de mecanismos de incentivos e de monitoramento, a fim de assegurar que o comportamento dos administradores esteja em conformidade com o interesse da empresa.

A governança da Tecnologia de Informação (GTI) surge como um subconjunto da governança corporativa, e tem elevada importância já que passa a ser um dos componentes importantes nas grandes organizações. Segundo Weill (2004), a GTI passou a ser adotada em tecnologia da informação para se referir aos critérios de definição, gestão e acompanhamento de resultados dos investimentos em Tecnologia de Informação (TI).

Deve-se compreender que dentro do processo da governança de Tecnologia da Informação existem vários métodos que servem como base para serem adaptados para a realidade em que se encontra a empresa, dentre os modelos mais conhecidos são: Control Objectives for Information and Related Technology (COBIT); Information Technology Infrastruture Library (ITIL); International Standards Organization (ISO), Balanced Scorecard (BSC) de TI, dentre outras metodologias. (FERNANDES, 2014).

Nesse contexto, a Universidade Potiguar (UnP) está inserida, pois é uma instituição que foi fundada em 1981 e é mantida pela Sociedade Potiguar de Educação e Cultura (APEC), que tem sede em Natal e integra o Sistema Federal de Ensino e pertence o grupo Laureate International Universities. A instituição utiliza o mecanismo de governança de TI, e é importante compreender como o modelo de GTI se aplica nas empresas, e a partir disso surge à pergunta problema: Como se aplica o modelo de governança de Tecnologia da Informação na empresa estudada?

\section{REFERENCIAL TEÓRICO}

Neste capítulo, são explanados os aspectos da teoria referentes ao assunto abordado, cujos objetivos já foram mencionados no início, para que se possam entender os aspectos que norteiam a aplicabilidade do modelo de governança de $\mathrm{TI}$, atingindo o objetivo principal de responder a pergunta problema. 


\subsection{Governança Corporativa: Origem e conceitos}

\subsubsection{O surgimento e conceitos de Governança Corporativa}

De acordo com o Instituto Brasileiro de Governança Corporativa (2009), o termo Governança Corporativa surgiu na década de 80 e 90, inicialmente nos Estados Unidos, onde se caracterizou por um movimento de acionistas e investidores que tinham o objetivo de se protegerem dos abusos praticados pela diretoria das empresas e com isso, viu-se a necessidade de um conjunto de regras e de sistemas de monitoramento tanto interno quanto externo que impedissem esses abusos.

O tema passou a ser mais discutido com o caso da empresa norte americana de energia Enron, como afirma Steinberg (2003), que em 2002 fraudou os resultados dos balanços para elevar o valor das suas ações. Com isso, houve a assinatura da lei Sarbanes-Oxley (SOX) nos Estados Unidos, como afirma Fernandes e Abreu (2014), o objetivo central dessa lei é proteger os investidores de capital de fraudes contábeis e também financeiras de companhias abertas, instituindo penalidades sobre esse tipo de crime.

No Brasil, o tema "Governança Corporativa" começou a ser discutido na década de 1990, com a criação do Instituto Brasileiro de Conselheiros de Administração (IBCA) que tinha o objetivo de discutir sobre os conselhos de administração, como afirma Steinberg (2003). Porém o IBCA se transformou em Instituto Brasileiro de Governança Corporativa (IBGC), pois passaram a tratar de questões que envolviam problemas relacionados aos conselhos fiscais, auditorias independentes, diretor-presidente (CEO) e acionistas, segundo Steinberg (2003). O IBCG e a Comissão de Valores Mobiliários (CVM) foram às primeiras instituições a lançarem códigos de boas práticas de Governança Corporativa.

Dentro desse contexto, de acordo com o Instituto Brasileiro de Governança Corporativa (IBGC, 2009), a governança corporativa é definida como um sistema onde as organizações são dirigidas, monitoradas e incentivadas, envolvendo os relacionamentos entre proprietários, Conselho de Administração, diretoria e órgãos de controle.

\subsubsection{Princípios da Governança Corporativa}

Em se tratando dos princípios que são considerados essenciais para garantir um bom sistema de governança corporativa, segundo o IBCG (2009), são os seguintes:

a) Transparência: caracteriza-se pela boa comunicação interna e externa que gera o ambiente de confiança dentro da organização, principalmente no momento de prestar informações sobre a empresa;

b) Equidade: ou seja, tratar de forma justa e igual todos os que fazem parte da empresa, principalmente os colaboradores, clientes, fornecedores, investidores, entre outros.

c) Prestação de Contas: é o momento em que os administradores e outros agentes da governança devem prestar contas de sua atuação;

d) Responsabilidade Corporativa: Os negócios devem ser conduzidos com o objetivo de alcançar a longevidade da empresa, incorporando decisões de ordem social e ambiental na definição dos negócios e operações que serão realizadas na empresa.

A figura 1 é o sistema de Governança Corporativa, segundo IBGC (2009): 


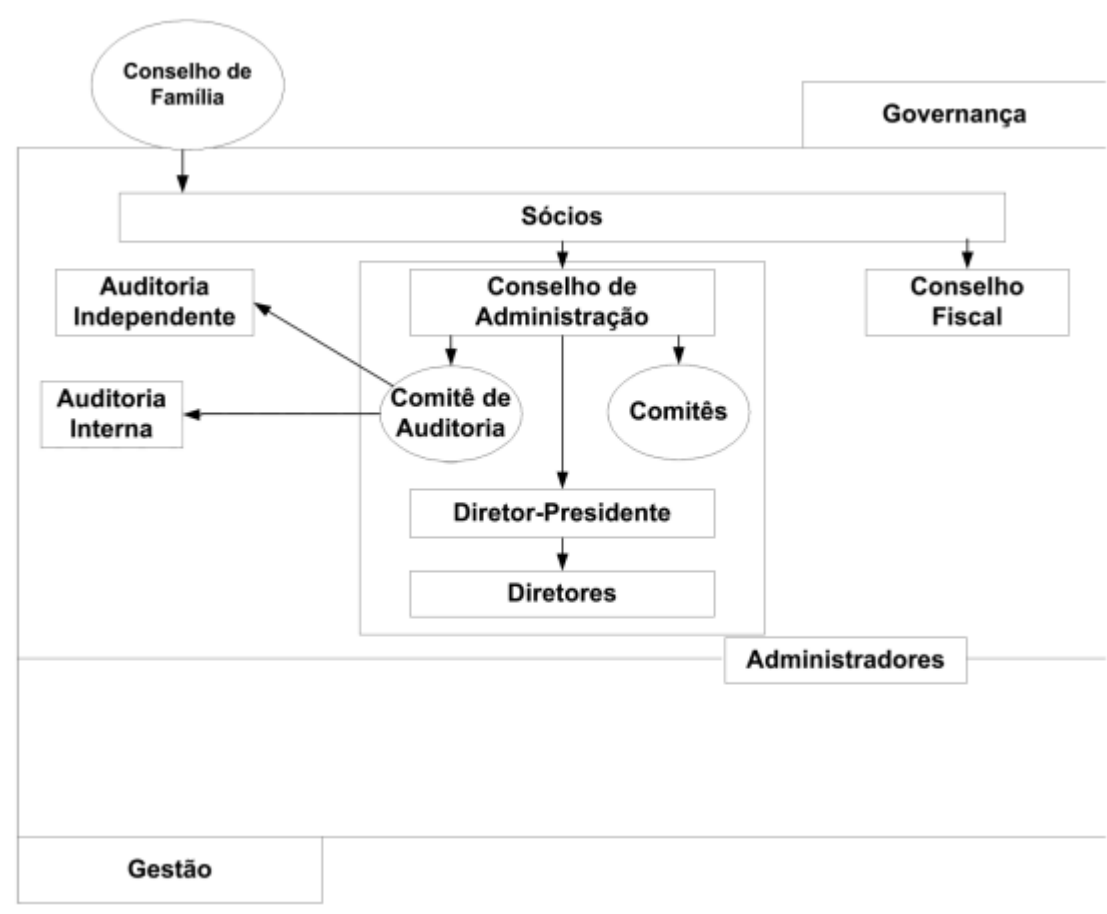

Figura 1 - Sistema de Governança Corporativa Fonte: IBCG (2009).

A figura 1 identifica os principais componentes de uma forma geral do sistema de Governança Corporativa.

\subsection{Governança da Tecnologia da Informação: conceito e implicações}

\subsubsection{Tecnologia da Informação}

Antes de falar sobre a Governança de $\mathrm{Tl}$, é preciso compreender a Tecnologia da Informação, que segundo Silva e Fleury (1999), são os recursos computacionais como hardware, software e serviços relacionados a eles, que provêm serviços de comunicação, processamento e armazenamento de dados. A partir desse conceito pode-se afirmar que a TI é um termo que engloba todas as formas de tecnologia, que são utilizadas como forma de armazenamento, criação, troca e uso das informações em várias formas.

Conforme esclarece Silva e Fleury (1999), o uso da TI é visto como um processo que passa pelo planejamento, avaliação do custo/benefício gerado pelo sistema e pela sua adequação à realidade da empresa. Trata-se de um processo de mudança que não só abrange o ambiente tecnológico, mas também o ambiente técnico, os recursos humanos e toda a estrutura da organização, segundo Teixeira (2004). Pode-se perceber que é relevante o uso da Tecnologia da Informação nas organizações visto que, segundo Albertin (2000), proporciona a inovação de muitos produtos e serviços como, por exemplo: entrega on-line de informação; acesso eletrônico a serviços; habilidade de solicitar e obter serviços específicos; o uso de produtos de software para pagamento e apresentação eletrônica de contas; além do fato de exercer grande influência no planejamento das organizações, colaborando desde a estratégia competitiva das empresas como também facilitar a entrada em alguns mercados (ALBERTIN, 2001); como também o fato de ser é responsável pelo armazenamento de dados provenientes do ambiente externo, que são as 
informações referentes ao relacionamento de uma empresa com seus clientes e/ou fornecedores, como esclarece Newel (2000).

\subsubsection{Governança de TI: Conceitos, objetivos e componentes}

É importante entender que a Governança de $\mathrm{TI}$, surgiu como um subconjunto da governança corporativa, e na figura 2, se vê a interação entre esses dois modelos.

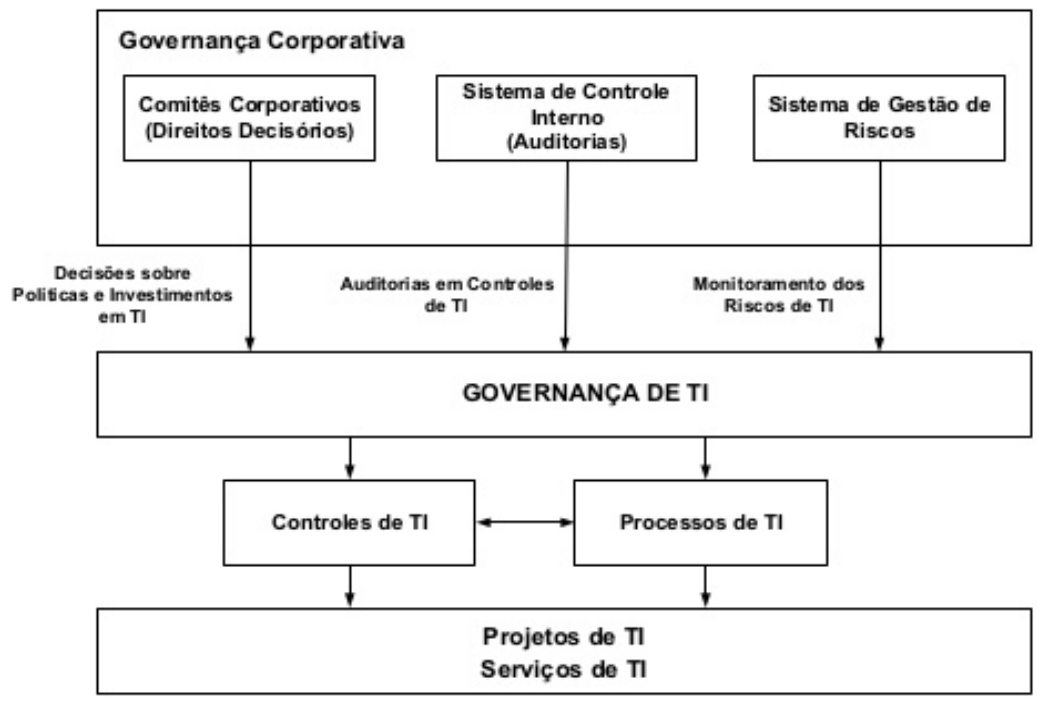

Figura 2 - Integração Governança Corporativa e Governança de TI . Fonte: Fernandes e Abreu (2014).

A figura 2 mostra que os sistemas de controle e risco e de direitos decisórios podem criar restrições para as operações e serviços de $\mathrm{TI}$.

A GTI pode ser motivada por vários fatores como afirma Fernandes e Abreu (2014), são eles: o ambiente de negócios, as integrações tecnológicas, a segurança da informação, os marcos de regulação e a dependência do negócio em relação a TI. Quando se refere ao ambiente de negócios no Brasil é caracterizado por uma competição muito intensa de novas empresas no mercado, pelo surgimento constante de produtos e serviços substitutos, além de novos concorrentes. Já as integrações tecnológicas são caracterizadas pelo uso de sistemas de gestão integrados. Outro aspecto motivador da Governança de TI é a segurança da informação que tem impacto direto na integridade do negócio.

Outro fator que se pode destacar são os marcos de regulação que representam restrições ao negócio, mas que devem ser seguidas. E a dependência do negócio em relação a TI que se trata de quanto mais operações que ocorrem nas organizações que dependem da tecnologia da informação; e TI como prestadora de serviços.

\subsubsection{Conceito de Governança de TI}

$\mathrm{O}$ conceito de Governança de TI surgiu em meio às mudanças das organizações em utilizar a Tecnologia da Informação como uma ferramenta de melhoramento de produtos e serviços, bem como o relacionamento cliente/empresa, influenciando todos os setores presentes na organização. 
Uma definição que se pode destacar é a da ISO/IEC 38500 (ABNT, 2009 apud. FERNANDES E ABREU, 2014, p.13), a GTI "é o sistema pelo qual o uso atual e futuro da TI são dirigidos e controlados. Significa avaliar e direcionar o uso da TI para dar suporte à organização e monitorar seu uso para realizar planos".

Fernandes e Abreu (2014) afirmam que a Governança de TI deve atingir três objetivos principais: promover o alinhamento da TI em relação ao negócio, no que se refere a aplicações, e a infraestrutura dos serviços; promover a implantação de mecanismos que garantem o processo continuo dos negócios; e por fim, promover o alinhamento de TI a marcos de regulação como a lei Sarbanes-Oxley.

\subsubsection{Ciclo da Governança de TI}

O ciclo da Governança de TI é composto por quatro etapas, como esclarece Fernandes e Abreu (2014), onde a primeira etapa é de Alinhamento Estratégico e Compliance que se refere ao planejamento estratégico da $\mathrm{TI}$, e leva em consideração as estratégias da empresa para seus produtos e segmentos, bem como os requisitos de Compliance externos, tais como o Sarbanes Oxley Act (SOX), o Acordo da Basiléia, entre outros. Já a etapa de Decisão, Compromisso, Priorização e Alocação de Recursos caracteriza-se pela decisão que são relativas a TI: Arquitetura, serviços de infraestrutura, investimentos, segurança da informação, objetivos de desempenho, dentre outras decisões. Esta etapa também trata da obtenção do envolvimento de tomada de decisões da empresa, assim como da definição de prioridades de projetos e serviços e da alocação efetiva de recursos financeiros.

A terceira etapa Estrutura, Processos, Operação e Gestão refere-se à estrutura organizacional e funcional de $\mathrm{Tl}$, aos processos de gestão e operação dos produtos e serviços de $\mathrm{TI}$, que devem estar em conformidade com as necessidades estratégicas e objetivos organizacionais da empresa. E a última etapa que é de Medição do Desempenho refere-se à determinação, coleta e geração de indicadores de resultados dos processos, produtos e serviços de TI, bem como a contribuição deles para a escolha de estratégias e objetivos do negócio.

Na figura 3, são os componentes inseridos no ciclo de governança de TI. 


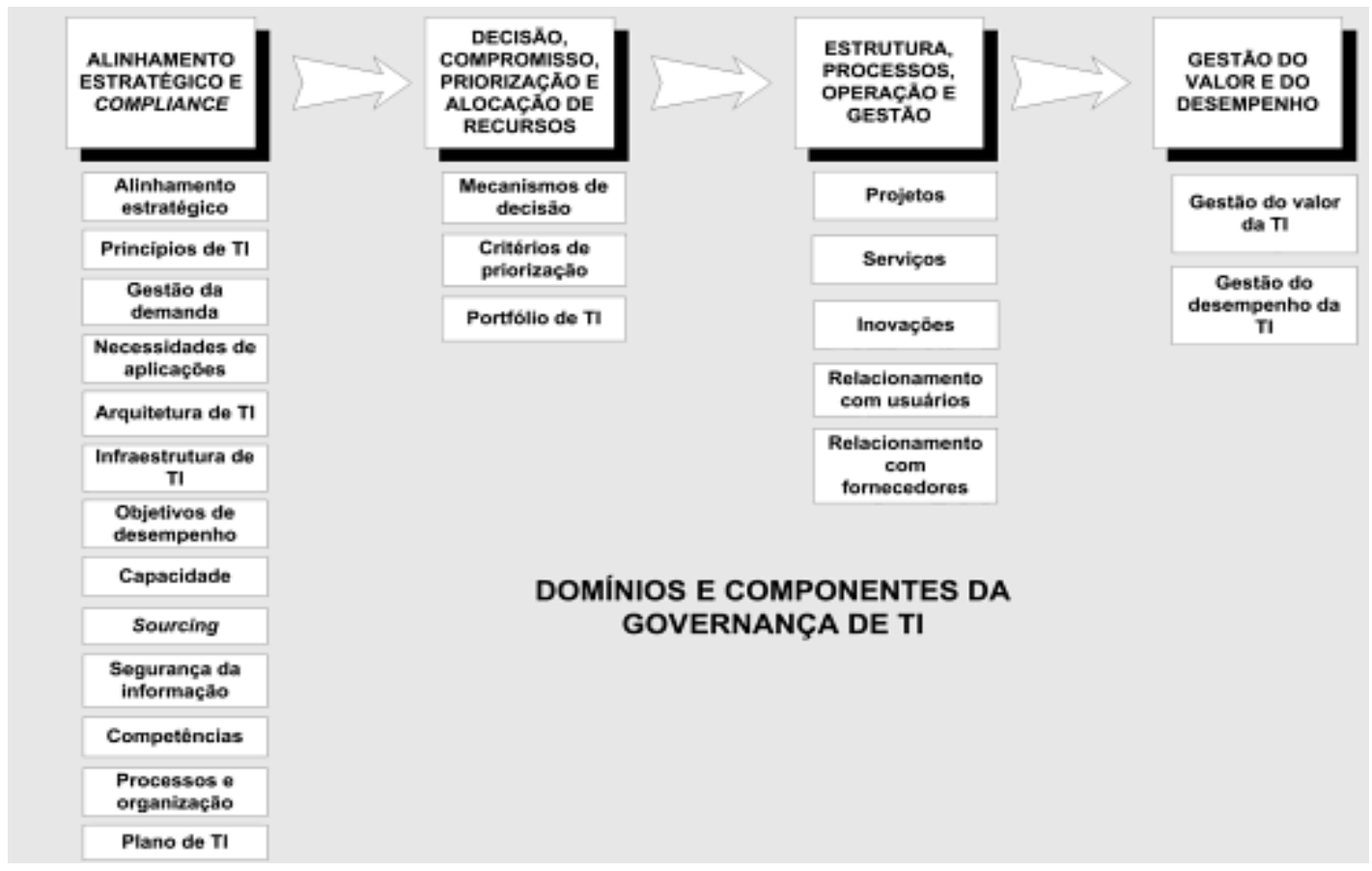

Figura 3 - Domínios e componentes de Governança de TI Fonte: Fernandes e Abreu (2014).

A figura 3 identifica os componentes e seus domínios que estão presentes em cada etapa do ciclo de governança de TI.

\subsubsection{Objetivos da Governança de TI}

Dentre os objetivos da GTI, o principal é que ela deve estar alinhada com os objetivos da empresa e sua realidade. A partir desse objetivo central, podem-se identificar outros objetivos da GTI, segundo Fernandes e Abreu (2014): Permitir a TI ter posicionamento mais claro dentro das áreas da organização; Alinhar e priorizar a TI com a estratégia de negócio; Alinhar a arquitetura e sua infraestrutura em relação às necessidades do negócio; Organizar a TI para a estrutura de processos de uma forma que possibilite a gestão do seu risco para que a atividade operacional continue sem interrupções; Organizar regras objetivas e claras sobre a responsabilidade de decisões e ações em relação a TI.

\subsection{O modelo de Governança de TI e suas características}

\subsubsection{Os modelos de melhores práticas para o uso da governança de TI}

No processo da governança de Tecnologia da Informação existem vários métodos que servem como base para serem adaptados para a realidade da organização. Algumas dessas metodologias serão descritas a seguir:

a) COBIT (Control Objectives for Information and related Technology): O COBIT,foi criado pela ISACA (Information Systems Audit and Control Association) e como afirma Caciato (2004), a sua estrutura se baseia em indicadores de performance, podendo-se monitorar o quanto a Tecnologia da Informação está agregando valores aos negócios da organização e sua metodologia é voltada para três níveis: os gerentes, usuários e os auditores; 
b) CMMI (Capability Maturity Model Integration): Metodologia desenvolvida pelo SEI (Software Engineering Institute), como um modelo de qualidade para o processo de engenharia de software. O principal objetivo desse modelo é fornecer diretrizes para melhores práticas para melhoria o processo de habilidades organizacionais, cobrindo o ciclo de vida de produtos e serviços. (FERNANDES e ABREU, 2008);

c) ITIL (Information Technology Infrastructure Library): foi criado pela Central Computing and Telecommunications Agency e reúne um conjunto de recomendações sobre suporte de serviços e entrega de serviços, como afirma Caciato (2004). Essa metodologia tem o objetivo de descrever os processos necessários para gerenciar a infraestrutura de $\mathrm{TI}$ de maneira eficaz para garantir os níveis de serviço para os clientes;

d) PMBOK (Project Management Body of Knowledge): como afirma Gama (2006), trata-se de manual que define e descrevem as habilidades, ferramentas e técnicas para o gerenciamento de um projeto;

e) BSC (Balanced Scorecard): desenvolvido por Robert Kaplan e David Norton, constituindo-se num novo modelo de gestão estratégica, baseado em indicadores financeiros e nãofinanceiros (KAPLAN e NORTON, 2006);

f) ISO (International Standards Organization): como afirma Gama (2006), é um conjunto de normas/padrões auditáveis de alto nível voltado ao cliente para sistemas de gerenciamento de qualidade. A ISO 9000, por exemplo, cobre o desenvolvimento de software, operações e serviços de TI, já o ISO 27001 refere-se a códigos de prática para a gestão da segurança da informação (FERNANDES e ABREU, 2006).

\subsubsection{Visão Geral do Modelo de Governança de TI}

Em se tratando do Modelo de Governança de TI, como afirma Fernandes e Abreu (2014), a figura 4 é um modelo de visão geral dos componentes que integram o processo de Governança de TI.

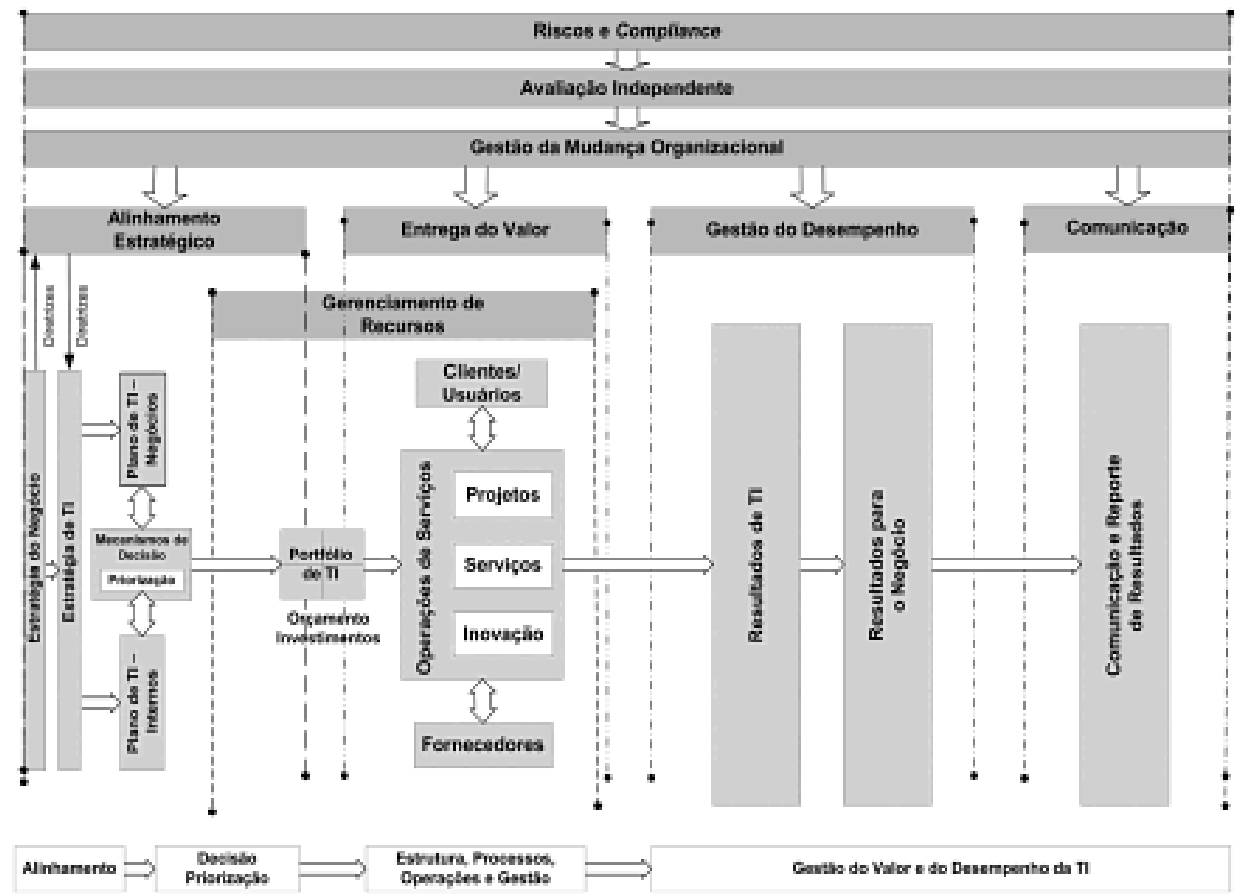

Figura 4 - Visão Geral do Modelo de Governança de TI Fonte: Fernandes e Abreu (2014). 
Definindo os componentes do modelo de governança de TI, segundo Fernandes e Abreu (2014): Riscos e Compliance que se trata da definição do nível tolerável de riscos da organização e também com o negócio em si; Avaliação Independente que se refere às auditorias que são feitas de forma independente; Gestão de Mudança Organizacional que é o processo de avaliação para implantar mudanças nas áreas de TI; Alinhamento Estratégico que consiste na interação entre a TI e alta administração da empresa, para estabelecer decisões no que se referem a objetivos estratégicos e de negócio que irão influenciar a área de TI; Entrega de Valor que se trata do gerenciamento de programas e projetos; Gestão de desempenho que é a definição de indicadores para analisar o desempenho da TI na empresa; Comunicação que se trata da relação do valor entregue da TI, com o negócio e o seu desempenho em relação às metas organizacionais; e o Gerenciamento de Recursos que consiste em administrar os investimentos na área de TI por meio de avaliações.

Inseridos no modelo de TI, estão os componentes de gestão e operacionais, que segundo Fernandes e Abreu (2014), são: Estratégia do Negócio que se trata do direcionamento dos objetivos estratégicos e planos; Estratégia de TI que se refere a elaboração de um plano levando em consideração a visão externa e interna da organização; Plano de TI - Negócios o qual são os projetos e inovações que são direcionados para o negócio; Plano de TI - Internos que são os projetos e serviços que a TI tem que implantar para atender ao Plano de TI-negócios; Mecanismos de decisão que trata-se de comitês para decisões para a área de TI; Portfólio de TI que refere-se a sua implantação após sua aprovação, logo após a priorização e quais os mecanismos que serão utilizados para o seu gerenciamento; Clientes/Usuários que são os processos de relacionamento de TI com os clientes da organização; Operações de Serviços que consiste no gerenciamento e execução dos projetos para o negocio e também para Tl; Fornecedores que é o gerenciamento de contratos que são fornecidos por terceiros; Resultados de TI que são os métodos para avaliar o desempenho e resultados, em relação a execução dos projetos e serviços estabelecidos; Resultados para o negócio que são os resultados alcançados pela TI para o negócio, como por exemplo, a redução de custos, aumento da rentabilidade, dentre outros; Comunicação e reporte de resultados que trata-se da comunicação para a alta administração e os executivos sobre o desempenho da TI.

\subsection{A Governança da Tecnologia da Informação e a vantagem competitiva}

\subsubsection{Vantagem Competitiva}

É possível perceber que com as mudanças organizacionais, a área de $\mathrm{TI}$, passou e ser um dos pilares principais de uma organização, pois segundo Albertin (2000), proporciona a inovação dos produtos e serviços, colaborando na estratégia competitiva da empresa.

Segundo Porter (1989), a vantagem competitiva ocorre quando uma empresa consegue criar uma competência ou valor superior, que a distingue das demais, para seus compradores. Porter (1989) também explica que vantagem competitiva é um conjunto de características que permite a uma empresa terem características diferentes por conseguir criar valor para seus produtos sob o olhar dos seus clientes/usuários, possibilitando a diferenciação frente a seus concorrentes e assim, a obtenção de vantagens no mercado. Já para Grant (2002, p.227 apud BRITO, 2012, p.364) a vantagem competitiva é quando duas ou mais empresas que competem em 
um mesmo mercado, a empresa que possui a vantagem competitiva é aquela que ganha (ou tem o potencial para ganhar) uma taxa do lucro persistentemente mais alta.

Como explica Porter (1991), existem três tipos de vantagens competitivas genéricas que são: liderança de custo, diferenciação e custo. $O$ autor explica que a liderança de custo consiste na empresa oferecer um produto padrão e procura obter vantagens de custo absoluto e de escala. A estratégia de diferenciação consiste em oferecer produtos, com características específicas, que permitam que cubra o seu preço, pois o elemento diferenciador de cada produto pode variar. Em relação à estratégia de enfoque ocorre quando a empresa opta por obter uma vantagem competitiva em apenas um segmento do mercado e, portanto, não tem uma vantagem competitiva geral.

\subsubsection{A governança de Tl e vantagem competitiva}

Como menciona Fernandes e Abreu (2014), a TI passa a ter maior será o papel estratégico para a empresa, pois as operações que ocorrem dentro da organização consequentemente tendem a depender mais dessa área, e com isso, a TI tem que cada vez mais estar alinhada com os objetivos organizacionais do negócio.

A TI está adquirindo uma função de agente de desenvolvimento e de definição de estratégias em diferentes níveis (corporativo, de negócio e até mesmo funcional), como explica Melo (2008). Para atender a essas necessidades, o modelo de sistemas de informação das organizações deve ser cada vez mais abrangente e flexível, e consequentemente a TI passa a ser vista como uma forma de obter vantagem competitiva já que essa área passa a exercer influencia em todos os setores da organização, no desenvolvimento e estratégia de novos produtos e serviços, assim fazendo com que a empresa se diferencie das suas concorrentes. E com isso, é necessário a empresa utilizar algum tipo de estratégia para alinhar a área de $\mathrm{TI}$ com o negócio, dentre eles está a governança de TI.

\section{METODOLOGIA}

Como procedimento metodológico adotado, em função dos objetivos, foi concebido como uma pesquisa exploratória e descritiva. As pesquisas exploratórias, segundo Gil (2007), são desenvolvidas com objetivo de proporcionar visão geral, acerca de determinado fato, ou seja, maior familiaridade com o problema, com vistas a torná-lo mais explícito ou a constituir hipótese.

Neste estudo também foi usada a pesquisa descritiva que segundo Alyrio (2008) busca essencialmente a enumeração e a ordenação de dados, sem o objetivo de comprovar ou refutar hipóteses exploratórias, abrindo espaço para uma nova pesquisa explicativa, fundamentada na experimentação.

A estratégia de pesquisa utilizada foi o estudo de caso, que segundo Yin (2005), é uma investigação empírica que permite o estudo de um fenômeno contemporâneo dentro de seu contexto da vida real. O objeto do estudo utilizado para a entrevista foi a Universidade Potiguar (UnP) que possui o mecanismo de Governança de $\mathrm{TI}$, com isso, pode-se analisar como esse mecanismo se aplica e se adequa a empresa mencionada.

Para coleta de dados foi feito uma entrevista semiestruturada, que segundo Lakatos (2004) é o tipo de entrevista que permite que o entrevistador tenha liberdade para desenvolver situações que considere adequada, podendo explorar mais a questão estudada. Como esclarece Triviños 
(1987), a entrevista semiestruturada tem como característica questionamentos básicos que são apoiados em teorias e hipóteses relacionados ao tema.

O instrumento de tratamento de dados utilizado foi à análise de conteúdo que segundo Bardin (2011), é um conjunto de técnicas de análise das comunicações visando a obter, por procedimentos sistemáticos e objetivos de descrição do conteúdo das mensagens, indicadores que permitam a inferência de conhecimentos relativos às condições de produção/recepção das mensagens.

No quadro a seguir, referem-se às categorias de análise para o tratamento de dados.

Quadro 1 - Categorias de análise

\begin{tabular}{|l|l|}
\hline Categoria & Definição \\
\hline $\begin{array}{l}\text { Governança } \\
\text { Corporativa }\end{array}$ & $\begin{array}{l}\text { "surge com o objetivo estabelecer um conjunto de mecanismos de } \\
\text { incentivos e de monitoramento" }\end{array}$ \\
\hline $\begin{array}{l}\text { Tecnologia de } \\
\text { Informação }\end{array}$ & $\begin{array}{l}\text { "recursos computacionais (hardware, software e serviços relacionados) } \\
\text { que provêm serviços de comunicação, processamento e armazenamento } \\
\text { de dados" }\end{array}$ \\
\hline $\begin{array}{l}\text { Governança } \\
\text { da Tecnologia } \\
\text { de Informação }\end{array}$ & $\begin{array}{l}\text { "passou a ser adotada em tecnologia da informação para se referir aos } \\
\text { critérios de definição, gestão e acompanhamento de resultados dos }\end{array}$ \\
\hline $\begin{array}{l}\text { Vantagem } \\
\text { Competitiva }\end{array}$ & $\begin{array}{l}\text { "é um conjunto de características que permite a uma empresa terem } \\
\text { características diferentes por conseguir criar valor para seus produtos sob } \\
\text { o olhar dos seus clientes/usuários." }\end{array}$ \\
\hline
\end{tabular}

\section{ANÁLISE E APRESENTAÇÃO DE RESULTADOS}

Esta etapa da pesquisa pretende analisar a Universidade Potiguar (UnP) que se utiliza do modelo de TI através dos dados obtidos com o instrumento de coleta de dados: a entrevista, realizada com Rousy Marry Queiroz, Coordenadora de Controles Internos de TI da universidade, a fim de que se possa entender como se aplica tal modelo, e os aspectos que o envolvem. A organização do capitulo se dará através de seções definidas pelas questões trabalhadas na entrevista.

\subsection{Aspectos Gerais sobre Governança Corporativa e Tecnologia da Informação}

É importante compreender que como afirma a Comissão de Valores Mobiliários (CVM, 2003), a governança corporativa como um conjunto de práticas que tem por finalidade aperfeiçoar o desempenho de uma organização ao proteger investidores, empregados e credores contra fraudes no balanço empresarial. E em se tratando dos aspectos da Governança Corporativa, segundo a entrevistada, a instituição a utiliza de maneira geral, pois ela garante a confiabilidade das operações tanto aos acionistas quanto aos clientes, já que possui políticas e normas internas, que são bem definidos e monitorados, garantindo eficiência e transparência.

É importante entender os conceitos que norteiam a visão geral do modelo de Governança de TI, dentre eles, a tecnologia da informação, e diante disso, notou-se que a TI é uma extensão da 
Governança Corporativa na Instituição, como explica a entrevistada, pois possuem processos, recursos e operação definidos e alinhados com a estratégia da Empresa, o que promove soluções tecnológicas inovadoras que agregam valor para a instituição, tanto para os clientes internos e externos, e a área de $\mathrm{TI}$ está distribuída no organograma da instituição da seguinte forma: Operações de Tl; Security Office, Escritório de Projetos, Desenvolvimento de Sistemas e de Controles Internos de TI, o qual o Diretor de TI está diretamente ligado a Presidência da instituição.

E quanto ao gerenciamento da área de Tl/Planejamento/Gestão de Recursos dentro da Organização, percebeu-se que assim como metas e estratégias estão diretamente ligadas às da Instituição, já que área de TI serve de apoio à estrutura educacional da instituição, ou seja, para processos e sistemas que demandam os serviços da TI.

\subsection{Governança da Tecnologia da Informação: Aspectos gerais e implantação do} modelo.

Em se tratando da Governança de TI, uma definição que se pode destacar é a da ISO/IEC 38500 (ABNT, 2009) apud. Fernandes e Abreu (2014, p.13), que define a GTI como o "sistema pelo o qual o uso atual e futuro da TI são dirigidos e controlados." Para a instituição, a governança de TI é de extrema importância, pois ela faz parte da estratégia que auxilia nos processos de outras áreas dando recursos de infraestrutura e sistemas e, também, faz parte das Auditorias que são realizadas na empresa, além de garantir integridade, disponibilidade, confiabilidade e confidencialidade dos serviços, informações e sistemas.

Como afirma Fernandes e Abreu (2014), a GTI é motivada por vários fatores, dentre eles: o ambiente de negócios; a segurança da informação; os marcos de regulação; a dependência do negócio em relação a TI e a TI como prestadora de serviços. Diante disso, os fatores determinantes para o uso desse modelo dentro da Organização, de acordo com a entrevistada, foram o fato de a empresa pertencer ao Grupo Internacional Laurate, a Segurança da Informação, confiabilidade dos sistemas e o negócio de modo geral.

Ainda de acordo com a entrevistada, para implantar o modelo de governança de $\mathrm{TI}, \mathrm{a}$ instituição enfrentou algumas dificuldades, dentre elas, a mudança de cultura organizacional, pois a instituição era um grupo familiar e que passou a pertencer a um grupo internacional, como também a burocratização de alguns processos e para minimizar essas dificuldades, foram realizados vários treinamentos com as equipes em relação ao entendimento das mudanças organizacionais e benefícios com o modelo da GTI, e também houve a implantação dos Controles Internos Financeiro e de TI, que validam e auditam todos os processos da instituição internamente.

Em se tratando do Ciclo de Governança de TI é composto por quatro etapas, como esclarece Fernandes e Abreu (2014): a etapa de Alinhamento Estratégico e Compliance se referem ao planejamento estratégico da TI; a etapa de Decisão, Compromisso, Priorização e Alocação de Recursos caracterizam-se pela decisão que são relativas a Tl: Arquitetura e infraestrutura, investimentos, segurança da informação, dentre outras decisões; a etapa Estrutura, Processos, Operação e Gestão referem-se à estrutura organizacional e funcional de TI; e a última etapa que é de Medição do Desempenho refere-se à determinação, coleta e geração de indicadores de resultados dos processos. 
Pode-se perceber que dentro da organização o ciclo acontece por inteiro, pois a definição das metas é alinhada ao negócio, incluindo normas, processos e responsáveis e os indicadores de desempenho da área de TI são acompanhados mensalmente, como também testes de resultados e medição de maturidade que são feitos por Auditorias Internas, SOX e Externas. Além do fato de que auditorias externas são feitas por quatro empresas independentes que são: Price Water House Coopers (PWC), Ernst Young (EY), KPMG e/ou Delloite (DTT).

É importante compreender que no processo da governança de Tecnologia da Informação existem vários modelos de melhores práticas para aplicação da governança de TI que servem como base para serem adaptados para a realidade da empresa. Diante disso, os principais modelos que a instituição utiliza são o Control Objectives for Information and related Technology (COBIT), Information Technology Infrastructure Library (ITIL), Project Management Body of Knowledge (PMBOK), ISO2700 e Scrum, onde cada modelo possui um setor responsável dentro da instituição, porém no caso do COBIT, o setor responsável tem a função do mapeamento de todos os processos e garantia de conformidade, utilizando as melhores práticas descritas no modelo. No caso do ITIL, o setor é responsável por ser o ponto único de contato do negócio com a TI, no qual faz toda a análise em 10 nível referente às demandas, sejam elas incidentes, mudanças ou acessos, para resolução. Em relação ao $\mathrm{PMBOK}$, se tem um Escritório de projetos que centraliza todas as demandas de novos projetos e faz o gerenciamento dos recursos, sejam eles de material ou headcount (termo utilizado pra se referir à mão de obra utilizada no processo). Em se tratando do ISO2700, se tem um Setor focado na análise e monitoramento da Segurança da Informação e por último o Scrum que é uma Metodologia Ágil de desenvolvimento de sistemas. Pode-se perceber que o uso dos modelos de melhores práticas garantem eficiência, eficácia e conformidade nos processos.

Diante da visão geral do modelo de Governança de Tecnologia como afirma Fernandes e Abreu (2014) à implantação desse modelo se dá de melhor forma quando se utiliza os modelos de melhores práticas e na instituição, a implantação do modelo de GTI ocorreu alinhada com o uso de todos os frameworks mencionados acima, pois regulamenta a forma correta e a melhor forma de garantir a integridade do negócio, bem como Segurança da Informação e confiabilidade dos sistemas e processos, além do fato de que os modelos de melhores práticas servem como suporte para melhor funcionamento da GTI na instituição, pois é realizado alinhamento no Comitê Executivo da Instituição, onde todas as decisões, projetos, propostas, planos, estratégias são informadas ao Comitê de $\mathrm{TI}$, do qual fazem parte os líderes de cada área, pois a área de TI está alinhada com os outros setores.

3.3 O uso do Modelo de Governança da Tecnologia de Informação como forma de obter vantagem competitiva.

Como esclarece Porter (1989) a vantagem competitiva é um conjunto de características que permite a uma empresa terem características diferentes por conseguir criar valor para seus produtos sob o olhar dos seus clientes/usuários, possibilitando a diferenciação frente a seus concorrentes.

Diante disso, pode-se perceber que para a instituição, em relação aos aspectos estratégicos, é preciso garantir que a GTI exista efetivamente na organização e que esteja nos requisitos de compliance, o que garante uma melhor colocação no mercado educacional, porém nos aspectos 
internos o uso da GTI garante que todos os seus recursos estão sendo utilizados da maneira correta, evitando risco de perdas financeiras, de imagem, de recursos, assim como fraudes, alcançando assim, resultados positivos com o uso desse modelo, pois houve a automatização e melhoramento dos serviços oferecidos na instituição e consequentemente houve redução de custos operacionais e financeiros, segundo a entrevistada.

\section{CONSIDERAÇÕES FINAIS}

No presente trabalho, objetivou-se analisar a instituição Universidade Potiguar (UnP) que está localizada no município de Natal, no Rio Grande do Norte, no que tange ao mecanismo de Governança de TI, procurando concluir e analisar como esse mecanismo se aplica e se adequa a empresa mencionada, bem como entender os conceitos que o norteiam.

No que tange a Governança Corporativa pode-se concluir que a instituição faz o uso desse mecanismo, pois ele garante a confiabilidade das operações tanto aos acionistas quanto aos clientes, já que possuem políticas e normas que são definidos e monitorados, o que garante eficiência e transparência do negócio, consequentemente diminuindo os riscos de fraudes.

Pode- se entender que com as mudanças organizacionais, a área de $\mathrm{TI}$, passou e ser um dos pilares principais de uma organização, e diante dessa perspectiva, na instituição a TI é uma extensão da Governança Corporativa, pois possuem processos, recursos e operação definidos e alinhados com a estratégia da empresa, pois serve de apoio à estrutura educacional da instituição, para processos e sistemas que demandam os serviços da $\mathrm{Tl}$ e ela se subdivide em cinco setores principais: Operações de TI; Security Office, Escritório de Projetos, Desenvolvimento de Sistemas e de Controles Internos de TI, o qual o Diretor de TI está diretamente ligado a Presidência Geral.

No que tange a governança de TI, pode-se concluir que para a empresa é de extrema importância, pois ela faz parte da estratégia que auxilia nos processos de outras áreas dando recursos de infraestrutura e sistemas e, também, faz parte das auditorias que são realizadas para monitorar todos os processos, e se estão ocorrendo da forma correta, garantindo integridade, disponibilidade, confiabilidade e confidencialidade dos serviços prestados, informações e sistemas desenvolvidos.

Em se tratando da implantação do modelo de Governança da Tecnologia da Informação, pode-se verificar que a empresa enfrentou dificuldades para implantá-lo, dentre eles, o principal foi à mudança de cultura organizacional, pois a instituição era um grupo familiar e passou a pertencer a um grupo internacional, como também a burocratização de processos e houve a implantação dos Controles Internos Financeiro e de TI, que validam e auditam os processos da instituição, sendo assim, os principais fatores que determinaram o uso de GTI foram o fato da empresa pertencer ao Grupo Internacional Laurate, a segurança da informação, confiabilidade dos sistemas e o negócio de modo geral. Outro fato que se concluiu é que a implantação do modelo se deu da melhor forma, pois ele está alinhado com o uso dos modelos de melhores práticas, sendo eles os principais modelos que a instituição utiliza: COBIT, ITIL, PMBOK, ISO2700 e SCRUM, onde cada modelo possui um setor responsável dentro da instituição, pois esses modelos regulamentam a forma correta e a melhor forma de garantir a integridade do negócio, bem como Segurança da Informação e confiabilidade dos sistemas e processos, e servem como suporte para melhor funcionamento da GTI. 
Pode-se entender também que o Ciclo de Governança de TI acontece por inteiro dentro da organização, pois a definição das metas, bem como as normas, processos e responsáveis por cada processo específico, onde os indicadores de desempenho da área de $\mathrm{Tl}$, testes de resultados e medição de maturidade são acompanhados mensalmente, que são feitos por Auditorias Internas, SOX e Externas, essas feitas por quatro empresas que são: Price Water House Coopers (PWC), Ernst Young (EY), KPMG e/ou Delloite (DTT), onde é realizado alinhamento no Comitê Executivo da Instituição, onde todas as decisões, tanto para projetos, propostas, planos e estratégias são informadas ao Comitê de $\mathrm{TI}$.

Pode-se considerar também que relacionando o uso do Modelo de Governança da Tecnologia de Informação como forma de obter vantagem competitiva, pode-se observar que, em geral, o uso da GTI garante que todos os recursos da área de TI estão sendo utilizadas da maneira correta, evitando risco de fraudes, perdas financeiras, de imagem, de recursos, bem como a segurança da informação, desde que essa área esteja alinhada com os objetivos organizacionais da empresa. Em relação aos resultados alcançados com o uso da área de $\mathrm{Tl}$ e consequentemente a GTI, a instituição tem obtido resultados positivos, pois houve a automatização e melhoramento dos serviços oferecidos e a redução de custos operacionais e financeiros.

Considera-se então, que o presente trabalho servirá como consulta acadêmica, tendo em vista que, pode-se observar como se aplica o modelo de governança de TI no caso estudado e abordado, na instituição Universidade Potiguar (UnP), bem como a ampliação dos conhecimentos sobre governança de TI, explicando os conceitos gerais, objetivos e princípios que o norteiam, considerando que a área de $\mathrm{Tl}$ é um dos componentes principais de uma organização.

\section{REFERÊNCIAS}

1. ALYRIO, R.D. Metodologia Científica. PPGEN: UFRRJ, Rio de Janeiro, 2008.

2. ALBERTIN, Alberto Luiz. Comércio eletrônico: modelo, aspectos e contribuições de sua aplicação. 2. ed. São Paulo: Atlas, 2000.

3. ALBERTIN, Alberto Luiz. Valor estratégico dos projetos de tecnologia da informação. Revista de Administração de Empresa. São Paulo, v.41, n.3, 2001.

4. BARDIN, L. Análise de conteúdo. Tradução de Luís Antero Reto e Augusto Pinheiro. 1. ed. São Paulo: Edições 70. 2011.

5. CACIATO, Luciano Eduardo. Métricas e metodologias do gerenciamento de TI. 2004. Disponível em: <http://www.timaster.com.br/revista/artigos/main_artigo.asp?codigo=980\& pag=1>. Acesso em: 05 jan. 2015.

6. FERNANDES, Aguinaldo Aragon; ABREU, Vladimir Ferraz de. Implantando a Governança de TI: Da Estratégia à Gestão dos Processos e Serviços. 1. ed. Rio de Janeiro: Braspot, 2006.

7. FERNANDES, Aguinaldo Aragon; ABREU, Vladimir Ferraz de. Implantando a Governança de TI: Da Estratégia à Gestão dos Processos e Serviços. 2. ed. Rio de Janeiro: Braspot, 2008.

8. FERNANDES, Aguinaldo Aragon; ABREU, Vladimir Ferraz de. Implantando a Governança de TI: Da Estratégia à Gestão dos Processos e Serviços. 4. ed. Rio de Janeiro: Brasport, 2014.

9. GAMA, Fernanda de Assis. Governança de Tecnologia da Informação: Um estudo em empresas brasileiras. Vitória. 2006.

10. GIL, A. C. Como elaborar projetos de pesquisa. 4. ed. São Paulo: Atlas, 2007.

11. Instituto Brasileiro de Governança Corporativa. Código das Melhores Práticas de Governança Corporativa. 4a edição, São Paulo: IBGC, 2009. 
12. Instituto Brasileiro de Governança Corporativa. Origens da Governança Corporativa. 2009. Disponível em: <http://www.ibgc.org.br/inter.php?id=18166>. Acesso em: 16 Jan. 2015.

13. KAPLAN, R. S, NORTON, D. P., Alinhamento: Utilizando O Balanced Scorecard para criar estratégias corporativas. São Paulo: Elsevier Editora Ltda., 2006.

14. LAKATOS, Eva Maria; MARCONI, Maria de Andrade. Metodologia Científica. 4 ed. São Paulo: Atlas, 2004.

15. MELO, D. R. A. A importância da tecnologia da informação nas estratégias das organizações contemporâneas: breve revisão de literatura. In: V CONGRESSO VIRTUAL BRASILEIRO DE ADMINISTRAÇÃO, 2008. Disponível em: <http://www.convibra.com.br/2008/artigos/412_ 0.pdf> Acesso em: 11 mar. 2015.

16. NEWELL, F. Fidelidade.com. São Paulo: Makron Books, 2000.

17. OLIVEIRA, R. V. A Lei Sarbanes-Oxley como nova motivação para mapeamento de processos nas organizações. In: ENCONTRO NACIONAL DE ENGENHARIA DE PRODUÇÃO, 26, 2006, Fortaleza.

18. PORTER, Michael. Estratégia competitiva: técnicas para análise das indústrias e da concorrência. 7. ed. , Rio de Janeiro: Campus, 1991.

19. PORTER, Michael. Vantagem competitiva: criando e sustentando um desempenho superior. 15. ed. Rio de Janeiro: Campus, 1989.

20. SILVA, S. M. K da; FLEURY, M.T.L. Aspectos culturais do uso de tecnologia de informação em pesquisa acadêmica. In: XXIII ENCONTRO DA ASSOCIAÇÃO NACIONAL DOS PROGRAMAS DE PÓS-GRADUAÇÃO, 23, 1999, Foz do Iguaçu.

21. STEINBERG, Herbert. A dimensão humana da governança corporativa: pessoas criam as melhores e as piores práticas. São Paulo: Gente, 2003.

22. TEIXEIRA, F; PONTE, V. M. R., Alinhamento Estratégico: Estudo Comparativo das Percepções dos Executivos de Negócios e de TI, XXVIII - Encontro da ANPAD. Anais. Curitiba, 2004.

23. TRIVIÑOS, A. N. S. Introdução à pesquisa em ciências sociais: a pesquisa qualitativa em educação. São Paulo: Atlas, 1987.

24. WEILL, P. O Segredo da Boa Governança. 2004. Disponível em: <http://download.micro soft.com/download/7/d/f/7df01ca4-4dd4-42f4-9c13-70a15d6e3450/MB32_Entrevista.pdf.>. Acesso em: 15 jan. 2015.

25. Universidade Potiguar. Institucional. Disponível em: www.unp.br/institucional/. Acesso em: 15 jun. 2015.

26. YIN, R. K. Estudo de caso: planejamento e métodos. 3. ed. Porto Alegre: Bookman, 2005.

\section{APÊNDICE}

\section{QUESTIONÁRIO UTILIZADO PARA COLETA DE DADOS REFERENTES AO TRABALHO DE CONCLUSÃO DE CURSO SUPERIOR DE TECNOLOGIA EM COMÉRCIO EXTERIOR.}

1 - A empresa utiliza Governança Corporativa? De que forma?

"A empresa, de modo geral, utiliza a Governança Corporativa uma vez que garante a confiabilidade de suas operações tanto aos acionistas quanto aos clientes, possui políticas e normas internas, processos bem definidos, monitorados, garantindo eficiência e transparência do negócio."

2 - Em relação a TI, qual a importância e influência dessa área para a empresa?

“A TI é uma extensão da Governança Corporativa na Instituição, possui processos, recursos e operação definidos e alinhados com a estratégia da Empresa, provendo soluções tecnológicas inovadoras que agregam valor para a 
instituição, para os clientes internos e externos e garantindo integridade, disponibilidade e confiabilidade dos serviços, informações e sistemas."

3 - Há algum tipo de gerenciamento da área de TI/Planejamento/Gestão de Recursos dentro da Organização? Como ocorre?

"Todo o gerenciamento, assim como metas e estratégias estão diretamente ligadas às da Instituição."

\section{4 - Qual a importância da Governança de TI para a empresa?}

"A governança de TI para a Empresa é de extrema importância pois faz parte da estratégia, auxilia nos processos de outras áreas dando recursos de infraestrutura e sistemas e, também, faz parte de escopo de Auditorias."

5 - Há alguns fatores que são motivadores para o uso da governança de TI nas empresas, como ambiente de negócios, segurança da informação, dependência do negócio com relação a TI, dentre outros fatores. Qual ou quais foram determinantes para o uso desse modelo dentro da Organização?

“O primeiro fator que determinou o uso de Governança de TI, assim como dos termos relacionados a Auditorias e Conformidades foi a empresa pertencer a um Grupo Internacional. A partir de então, outros fatores como Segurança da Informação, confiabilidade dos sistemas e o negócio de modo geral determinaram a continuidade desse trabalho."

\section{6 - Referindo-se ao ciclo de governança de TI, de que forma as etapas que o compõem acontecem dentro da empresa?}

“O Ciclo acontece por inteiro, a definição das metas é alinhada ao Negócio, temos normas, processos e responsáveis bem definidos, indicadores de desempenho que são acompanhados mensalmente, testes de resultados e medição de maturidade feito por Auditorias Internas, SOX e Externas (essa última realizada pela Price water house Coopers (PWC), Ernst Young (EY), KPMG e/ou Delloite - DTT)".

7 - Quais são os benefícios do uso do modelo GTI?

"Garantir integridade, disponibilidade e confiabilidade dos serviços, informações e sistemas."

8 - A empresa enfrentou algum tipo de dificuldade para implantar a governança de TI? Se sim, como foi resolvido?

"Sim, a maior dificuldade foi a mudança de cultura Organizacional e a burocratização de alguns processos. Para minimizar essas duas dificuldades, foram realizados vários treinamentos com as equipes para entendimento das mudanças e benefícios com o novo modelo, além da implantação dos Controles Internos Financeiro e de TI, que validam e auditam a instituição internamente."

9 - A empresa utiliza algum modelo de melhores práticas para aplicação da governança de TI como Cobit, Itil, PMBOK, entre outros modelos? Se sim, qual e de que maneira é aplicado e gerenciado?

"COBIT: temos um Setor responsável pelo mapeamento de todos os processos e garantia de conformidade, utilizando as melhores práticas descritas no Cobit. ITIL : temos um Setor responsável por ser o ponto único de contato do negócio com a TI, no qual faz toda a análise em 10 nível referente às demandas, sejam elas incidentes, mudanças ou acessos, para resolução. Além de sistema trabalhando totalmente com os conceitos do ITIL. PMBOK: temos um Escritório de projetos que centraliza todas as demandas de novos projetos e faz o gerenciamento dos recursos, sejam eles de material ou headcount, alinhando com o Comitê Executivo da Instituição. ISO27000: temos um Setor focado na análise e monitoramento da Segurança da Informação. SCRUM: Metodologia Ágil de desenvolvimento de sistemas."

10 - Quais os benefícios do uso dos modelos de melhores práticas para a empresa?

"O maior benefício é seguir as melhores práticas do mercado que garantem eficiência, eficácia e conformidade em nossos processos." 
11 - Para o uso da GTI, há algum tipo de gerenciamento/Planejamento/Gestão? De que forma ele ocorre?

"Tudo o que é determinado, desde a mudança de um processo quanto a mudança de uma ferramenta é planejado com os principais envolvidos e, posteriormente, documentado, validado e disponibilizado para todos os colaboradores."

12 - Como a empresa vê a GTI como uma forma de obter vantagem competitiva em relação a suas concorrentes? De que forma isso acontece?

"Com a GTI a empresa tem a garantia que todos os seus recursos estão sendo utilizados da maneira correta, evitando risco de perdas financeiras, de imagem, de recursos, assim como fraudes."

13 - Dentro da visão geral do modelo da GTI e da realidade da empresa, como se dá a sua implantação?

"O modelo de GTI com todos os frameworks escolhidos listados no quesito anterior estão implantados."

14 - Inseridos no modelo de governança de TI estão os componentes de gestão e operacionais, como por exemplo, Estratégia de Negócio, Estratégia de TI, Planos de TI, Resultados de TI entre outros, de que forma esses componentes estão distribuídos, levando em conta a realidade da empresa?

“É realizado alinhamento no Comitê Executivo da Instituição, do qual o Diretor de TI é integrante, e todas as decisões, projetos, propostas, planos, estratégias são informadas ao Comitê de TI, do qual fazem parte os líderes de cada área. O Planejamento Estratégico de TI é totalmente alinhado com o da Instituição."

15 - Em relação aos resultados do uso da área de $\mathrm{TI}$ e consequentemente a GTI, a empresa tem obtido resultados positivos ou negativos?

"Positivos." 